\title{
Widespread Tophi Found Incidentally on 18-FDG-PET/CT
}

\author{
Ji-Min $\mathrm{Oh}^{1}$, Won Young $\mathrm{Kim}^{2}$ \\ Departments of Internal Medicine ${ }^{I}$ and Radiology ${ }^{2}$, Anyang SAM Hospital, Anyang, Korea
}

\section{Case Report}

This 54-year-old man has been treated for chronic tophaceous gout since 1993. His past medical history included hypertension, chronic kidney disease and left hip arthroplasty due to traumatic fracture. On physical examination, there were multiple nontender masses on the elbows, metacarpophalangeal joints, proximal interphalangeal joints (hands), knees, ankles and the first metatarsophalangeal joints. The serum uric acid level was $6.0 \mathrm{mg} / \mathrm{dL}$ (reference, $3.0 \sim 8.0 \mathrm{mg} / \mathrm{dL}$ ) on 40 $\mathrm{mg}$ of febuxostat. The serum creatinine level was $0.8 \mathrm{mg} / \mathrm{dL}$ (reference, $0.6 \sim 1.2 \mathrm{mg} / \mathrm{dL}$ ) and creatinine clearance was 84.9 $\mathrm{mL} / \mathrm{min}$ (reference, $75.0 \sim 125.0$ ) by application of the Cockcroft-Gault equation.

The patient complained of voiding difficulty. The finding from ultrasonography of the prostate suggested a diffuse decreased echogenicity on the peripheral zone. The prostate specific antigen was elevated $(15.95 \mathrm{ng} / \mathrm{mL}$, reference, $0 \sim 4)$. The result of a prostate biopsy showed adenocarcinoma. An 18Fluorodeoxyglucose positron emission tomography (FDG PET) computed-tomography (CT) scan was performed for staging work-up. PET/CT showed multiple amorphous masses around the articular cartilages with hypermetabolicity (Figure 1).

\section{Discussion}

PET/CT has been used in the evaluation of malignancy, cancer staging, surgical planning and radiation therapy. But, because it is highly sensitive, false positive results are often possible. For example, false positives can be produced by stomas, hernias, physiologic muscle uptake and tophaceous gout (1). Tophi on PET/CT scans are seen as focal FDG uptake in juxta-articular soft-tissue-density masses (2). Unlike metastasis to bone, tophi are mostly located within around the non-axial skeleton, with or without associated erosions. In a gouty arthritis patient, PET/CT is valuable in detecting tophi
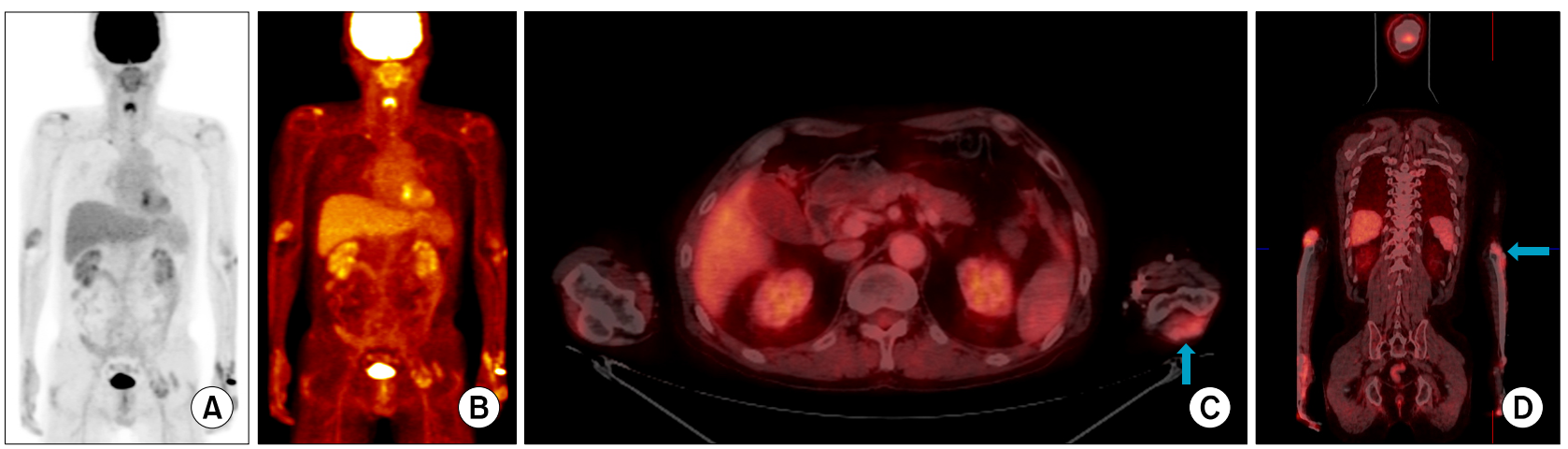

Figure 1. (A, B) Multiple nodular or amorphous hypermetabolic sites are noted around the joints of both shoulders, elbows, wrists, and hips on FDG-PET/CT. (C, D) Dense amorphous masses around the joints space of both elbows, which are hypermetabolic on FDG-PET/CT.

<Received : July 27, 2013, Revised : October 23, 2013, Accepted : October 23, 2013>

Corresponding to: Ji-Min Oh, Department of Internal Medicine, Anyang SAM Hospital, 9, Samdeok-ro, Manan-gu, Anyang 430-733, Korea. E-mail: ninijang@naver.com

pISSN: 2093-940X, elSSN: 2233-47I8

Copyright (c) 2013 by The Korean College of Rheumatology

This is a Free Access article, which permits unrestricted non-commerical use, distribution, and reproduction in any medium, provided the original work is properly cited 
on sites that are hard to examine such as the hip or spine. Also, PET/CT shows that tophi reveal significant inflammation (3).

The modalities used in gout have diversified. Dual energy CT has been utilized as a noninvasive method to determine urate deposits, particularly when a synovial fluid examination is negative or unobtainable (4). It is expected that PET/CT may play a helpful role in gout diagnosis and in effective evaluation of treatment.

\section{References}

1. Blumer SL, Scalcione LR, Ring BN, Johnson R, Motroni B, Katz DS, et al. Cutaneous and subcutaneous imaging on FDG-PET: benign and malignant findings. Clin Nucl Med 2009;34:675-83.

2. Ito K, Minamimoto R, Morooka M, Kubota K. A case of gouty arthritis to tophi on 18F-FDG PET/CT imaging. Clin Nucl Med 2012;37:614-7.

3. Su H, Li X, Zhao N, Zou H, Jiang L, Zhou Y. Comparing the usefulness of four imaging techniques in the same gouty arthritis patient. Int J Rheum Dis 2012;15:e128-30.

4. Dalbeth N, Doyle AJ. Imaging of gout: an overview. Best Pract Res Clin Rheumatol 2012;26:823-38. 